\title{
Integrated Model of the Ecological-Economic System for Managing the Coastal Pollution Inflow to the Sea Bay
}

\author{
I. E. Timchenko*, I. K. Ivashchenko, E. M. Igumnova, S. V. Svishchev \\ Marine Hydrophysical Institute of RAS, Sevastopol, Russian Federation \\ *timchenko.syst.analysis@mhi-ras.ru
}

Purpose. The paper is aimed at describing the improved integrated model of the ecological-economic system "coast-bay" permitting to control the balance of rates of accumulation and destruction of the pollutants entering the sea with coastal runoff.

Methods and Results. The model is based on the concept of mutual adaptation of the simulated processes' deviations from their standard values under the influence of external forces. The average multi-year values of the simulated processes are used as a stationary state of the system. The scheme of the cause-effect relationships between the development of the biochemical processes in the marine ecosystem and the economic processes of consumption and reproduction of the marine biological and assimilation resources is proposed. The scheme contains the logical agents for managing the scenarios of these processes based on the criteria of the pollution and biodiversity levels of the marine environment. The system dynamic model was constructed using the method of adaptive balance of causes in which, in order to assess the influence coefficients, a new presentation of the normalized relations of the standard mean values is used. The current values of the simulated processes are used in the coefficient estimates. To test correspondence of the model scenarios to real processes, the computational experiments including the model of the ecological-economic system "coastal runoff-the Sevastopol Bay ecosystem" were performed. The observations-derived average multi-year values of phyto-, zoo-, bacterio-plankton, nitrates, ammonium, dissolved organic matter and detritus concentrations were used in the model.

Conclusions. The results of the experiments confirmed possibility of managing the forecasted scenarios of the ecological and economic processes in accordance with the management concepts embedded in the model. The scenarios' response to different variants of the external managing actions is shown, that makes such models a convenient tool for planning the nature-protection measures within the "coast-bay" systems.

Keywords: adaptive model, ecological-economic system, biodiversity index, pollution level index, profitability, management agents, Sevastopol Bay.

Acknowledgements: resource potential of the coastal zone was investigated within the framework of the state task on theme No. 0827-2018-0004 "Complex interdisciplinary investigations of the oceanologic processes conditioning functioning and evolution of the Black and Azov seas' ecosystems of coastal zones". The model for managing the processes in the system "coast-the Sevastopol Bay" was developed and the computational experiments were performed at the RFBR and Sevastopol government financial support within the framework of scientific project No. 18-47-920001 "Study of the principles for constructing adaptive models of the ecologicaleconomic systems and digital information technologies for managing the scenarios of sustainable development of the nature-economic complexes in the Sevastopol region".

For citation: Timchenko, I.E., Ivashchenko, I.K., Igumnova, E.M. and Svishchev, S.V., 2020. Integrated Model of the Ecological-Economic System for Managing the Coastal Pollution Inflow to the Sea Bay. Physical Oceanography, [e-journal] 27(3), pp. 305-316. doi:10.22449/1573-160X-2020-3-305-316

DOI: 10.22449/1573-160X-2020-3-305-316

(C) I. E. Timchenko, I. K. Ivashchenko, E. M. Igumnova, S. V. Svishchev, 2020

(C) Physical Oceanography, 2020

Introduction. One of the problems of the sea coastal zone ecological economy is the control over the pollution level and marine environment biological diversity under effect of household, industrial and agricultural waste coming from the coast 
[1-17]. In works [6, 8, 18-21], the concept of contaminated wastewater flow control based on integral indices of pollution, biodiversity and economic feasibility of discharging these waters into the sea, taking into account penalties imposed for pollution, is proposed. On the basis of this concept, an adaptive model of ecological-economic system of the coast - sea natural-economic complex was created by the method of adaptive balance of causes [19], which makes it possible to control the integral balance of inflow and destruction rates of pollutants in the sea. It was assumed that marine ecosystem assimilation capacity is determined by the intensity of the processes of harmful substances biochemical decomposition, which depends on a number of natural and anthropogenic factors: the nature and volume of household, river and rainwater runoffs, sea temperature, dynamic activity of water masses, etc. [7-16, 22].

Depending on the nature of the coastal runoff, each section of the coastal zone is a separate natural and economic complex of the coast - sea type, which has its own characteristics. An example of such a complex is the coast - the Sevastopol Bay ecological and economic system, which is one of the most polluted areas of the coastal zone. Despite the difference in the conditions for the accumulation and destruction of pollutions, for all coastal zone natural complexes, a general integral model of pollutant flow control based on the principles of environmental control can be proposed.

Purpose. The present study is devoted to the improvement of integral model for managing the ecological state of the sea bay [20]. The presented model is based on the idea of managing the balance of two interrelated indices of the marine environment state: the pollution level and the biodiversity level. A method for controlling these indices by the degree of their deviation from the maximum permissible values characterizing the limits of the marine ecosystem stability is proposed. A new method for assessing the effect coefficients in the adaptive model of the ecological-economic system was applied.

The proposed model for managing the assimilation capacity of the bay is based on a number of assumptions. The management task was to monitor the consumption and reproduction integral balance of two main types of marine environment resources: biological and assimilation ones. A weighted sum of the biological objects concentrations, which, according to long-term observations, constitute the basis of the food chain of the bay marine ecosystem, is considered as a biological resource. This resource is represented by $B D$ biodiversity index. It was considered that due to the water masses transfer and diffusion, there is a concentration of substances averaged over the bay volume that form the integral index of the pollution level $P L$, which depends on the intensity and duration of the pollution coastal runoff. The assimilation resource was determined by integral balance $S$ of the volumes of pollution entered the sea $P L_{\text {acc }}$ and that part of them which was neutralized for a certain period of time $(0, t)$ by biochemical destruction. The integral balance was characterized by the difference in the inflow and destruction rates of pollutants. It was assumed that with an increase in this difference, the pollution concentration $P L$ increased and the value of biodiversity index $B D$ decreased. The task was to limit the flow of pollutants entering the sea by imposing $T X$ penalties on the coastal social-economic system, which increase 
the cost of its operation, since it forces it to invest additional funds in treatment facilities to maintain production volumes $V$.

Materials and methods. For constructing a formal mathematical management model, the concept of an adaptive balance of development processes in the system is formulated. The concept assumed that the average long-term values of all simulated processes $u_{i}$, which were taken as the vector of the system stationary state $C_{i}$, are known. The management model controlled the dynamics of biodiversity level $B D^{\prime}=B D-C_{B D}$, varying in the vicinity of the biodiversity index stationary value $C_{B D}$, and the pollution level $P L^{\prime}=P L-C_{P L}$, varying in the vicinity of stationary value $C_{P L}$. Both indices characterized the marine environment assimilation capacity: they took on their minimum and maximum permissible values $B D^{*}$ and $P L^{*}$ when the equality of the possible rates of pollution accumulation and destruction reached its maximum, which depended on the volume and nature of coastal runoff, as well as on the marine environment dynamics and ecological state.

All processes in the coast - bay system were considered adaptive, since it was assumed that the system possesses certain stability: it returned to its stationary state when the external causes that brought it out of this state ceased to act. This assumption made it possible to apply the adaptive balance of causes method ( $A B C$ method $[6,20])$ to construct a formal model of the system, in which negative feedbacks between processes $u_{i}$ and their variation rates are embedded in the structure of the method equations and provide a dynamic adjustment of processes to each other and to external effects. At the same time, material balances of the reactions of substances interaction were preserved in each of the equations:

$$
u_{i}=C_{i}+\sum_{k=1}^{m} a_{i k}\left(u_{k}-C_{k}\right)-\sum_{l=1}^{n-m} a_{i l}\left(u_{l}-C_{l}\right)-A_{i},
$$

where $a_{i k}$ and $a_{i l}$ are the coefficients of positive and negative effects that took into account intrasystem interactions of the development processes; $A_{i}$ are the external effects.

The system of the method equations maintaining the material balances (1) had the following form

$$
\begin{gathered}
\frac{d u_{i}}{d t}=2 r_{i} u_{i}\left\{C_{i}-\left[u_{i}-\sum_{k=1}^{m} a_{i k}\left(u_{k}-C_{k}\right)+\sum_{l=1}^{n-m} a_{i l}\left(u_{l}-C_{l}\right)-A_{i}\right]\right\} ; \\
u_{i}=\operatorname{IF}\left[u_{i}<0 ; 0 ; \operatorname{IF}\left(u_{i}>2 C ; 2 C_{i} ; u_{i}\right)\right] .
\end{gathered}
$$

where $r_{i}$ are specific rates of $u_{i}$ functions variation; $n$ is a number of modeled processes; $m$ is a number of positive effects. Conditions (3) have managed the finding of solutions for model equations within the variability intervals of $\left(0 \leq u_{i} \leq 2 C_{i}\right)$ variables. 
Now we are to consider the processes in the coast - bay ecological-economic system (indicators of the coastal system economic activity and the concentration of substances in the sea) as a reaction of transforming the system resources into its products. As the product amount is added up as a result of positive and negative increments of its mass, the positive effects of processes on each other cause positive increments in the mass of products, and negative effects cause negative increments. In order to assess the coefficients of effects, in this work we used a method that takes into account the relative weight of the effects changing over time. All the effects were considered as current contributions of resources $u_{j}^{\prime}=u_{j}-C_{j}$ to the formation of product $u_{i}$. Therefore, for all resource variables, reduced to the product dimension by multiplying by the ratio of mean values $C_{i} C_{j}^{-1}$, the current relative weights of effects were introduced. For example, for the case of two positive effects subject to the condition of maintaining the material balance:

$$
u_{1}=C_{1}+a_{12} C_{1} C_{2}^{-1} u_{2}^{\prime}+a_{13} C_{1} C_{3}^{-1} u_{3}^{\prime},
$$

current coefficients of relative effects had the form

$$
a_{12}=\frac{C_{2}^{-1} u_{2}}{C_{2}^{-1} u_{2}+C_{3}^{-1} u_{3}} ; \quad a_{13}=\frac{C_{3}^{-1} u_{3}}{C_{2}^{-1} u_{2}+C_{3}^{-1} u_{3}} .
$$

Thus, the effect coefficient $a_{i j}$ in the case of $m$ effects could be written down as follows:

$$
a_{i j}=C_{j}^{-1} u_{j}\left(\sum_{j=1, j \neq i}^{m} C_{j}^{-1} u_{j}\right)^{-1} .
$$

Note that in the expressions for the normalized coefficients of effects, not the deviations of the variables from the mean values but the non-negative variables themselves were used. This excluded the vanishing of the denominators of these coefficients.

Taking into account the proposed estimates of the effect coefficients, the system of equations of the adaptive model (2) for $m$ positive and $n-m$ negative effects was modified as follows:

$$
\begin{aligned}
& \frac{d u_{i}}{d t}=2 r_{i} u_{i}\left\{C_{i}-\left[u_{i}-\sum_{k=1, k \neq i}^{m} C_{k}^{-1} u_{k}\left(\sum_{k=1, k \neq i}^{m} C_{k}^{-1} u_{k}\right)^{-1} C_{i} C_{k}^{-1} u_{k}^{\prime}+\right.\right. \\
& \left.\left.+\sum_{l=m+1, l \neq i}^{n} C_{l}^{-1} u_{l}\left(\sum_{l=m+1, l \neq i}^{n} C_{l}^{-1} u_{l}\right)^{-1} C_{i} C_{l}^{-1} u_{l}^{\prime}-A_{i}\right]\right\} .
\end{aligned}
$$

Analysis of the results. We assume that the coastal social-economic system supplies the marine environment of the bay with a constant flow of pollutants due to the volume of production $V$. We assume that at the initial moment of time the marine environment was in a stationary ecological state, in which the balance of accumulated volumes of pollutants received and assimilated by the environment, 308 
indicated as $S(t)$, remained equal to zero. This means that the rates of pollution inflow and their destruction were equal. With an increase in the flow of pollutants, a moment of time came when the rate of their destruction began to lag behind the rate of their entry and an imbalance in the volumes of incoming and assimilated pollutants arose. Above we designated the value of biodiversity index at the maximum possible rate of pollution assimilation as $B D^{*}$ and the corresponding maximum allowable value of pollution concentration as $P L^{*}$. From this point in time, the coast - sea bay control system had to limit the rate of pollutant inflow into the sea in order to restore the zero balance $S(t)$.

To control the integral balance of the rates of pollutant inflow and assimilation in the management model, the logical agent of assimilation capacity $R(t)$, which reacted to the excess of $P L^{*}$ value by the pollution level index $P L$, was applied. This corresponded to the biodiversity level decrease to the value $B D<B D^{*}$. It was also assumed that the maximum value of pollution concentration was $2 C_{P L}>P L^{*}$. Thus, the coast - sea bay system was on the upper boundary of possible stationary states at the maximum permissible values of pollution and minimum permissible values of biodiversity concentrations.

The introduced assumptions allowed expressing the balance of the amount of pollution entered and assimilated by the marine environment, by the formula

$$
S(t)=a_{P L / V} \int_{0}^{t}[1-R(\tau)] V(\tau) d \tau, \quad 0 \leq R(t) \leq 1,
$$

in which the assimilation capacity agent $R(t)$ had the following representation:

$$
R(t)=I F\left\{P L<P L^{*} ; 1 ; I F\left[T X_{\text {acc }}<T X_{\text {acc }}^{*} ; \exp \left(-\alpha_{R} \tau\right) ; 1+(R(t)-1) \exp \left(-\beta_{R} \tau\right)\right]\right\},
$$

where $a_{P L / V} V$ is a current volume of discharged pollutions; $T X_{\text {acc }}$ is the available volume of economic system funds accumulated for marine pollution abatement; $T X_{\text {acc }}^{*}$ is the required amount of these funds.

In order to manage the ecological state of the bay, a scheme of cause-effect relationships between the processes of a generalized production output in the coastal social-economic system and biochemical processes developing in the coastal marine ecosystem was proposed (Fig. 1). With the growth of production output, the level of sea pollution increased and the integral balance of pollution accumulation and destruction volumes varied. This entailed a decrease in biodiversity index $B D$ and its deviation from the minimum permissible value $B D^{*}$ characterizing the bioresource and, consequently, assimilation capacity of the marine environment. Negative values of $B D-B D^{*}$ difference served as a signal for the management system, which limited the volume of pollutant discharge into the bay through the agents of biodiversity $A G_{B D}$ and production management $A G_{V}$. 


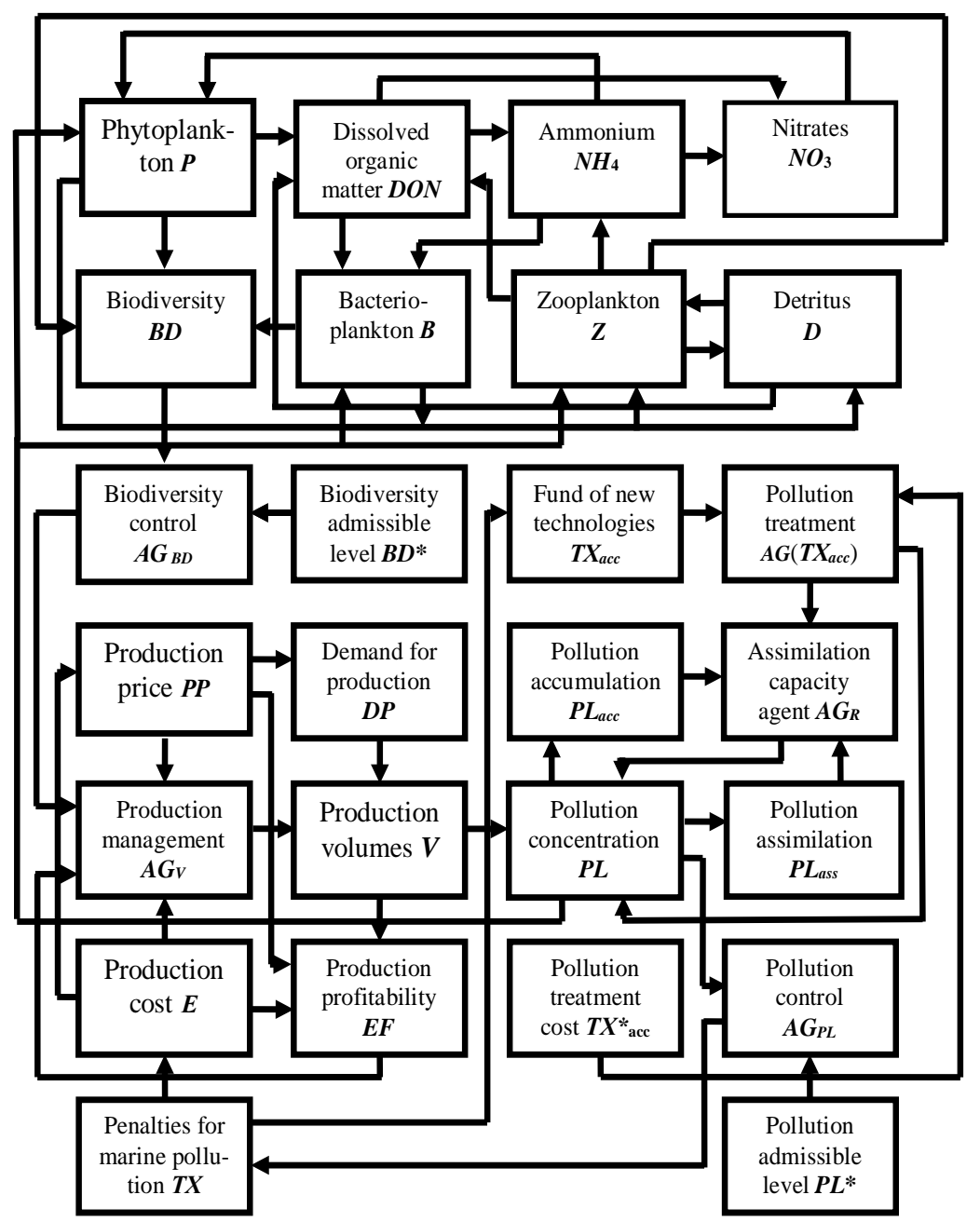

F i g. 1. Ecological-economic model for managing the coastal pollution runoff

The coast - bay ecological-economic system formal model was based on the adaptive model of management, published in a number of articles [18, 20]. The difference of this model consisted in the fact that it used the above-discussed new scheme for assessing the effect coefficients based on the ratios of average values of the simulated processes. Therefore, the scheme of mutual effects shown in Fig. 1 provided the conservation of material balances (1) for all variables of the coast - bay system. The concentrations of phytoplankton $P P$, zooplankton $Z P$, bacterioplankton $\mathrm{B}$, nitrates $\mathrm{NO}_{3}$, ammonium $\mathrm{NH}_{4}$, dissolved organic matter $\mathrm{DON}$ and detritus $D$ were used as elements of the marine ecosystem by analogy with work [17]. The dynamic model of the bay ecosystem was constructed on the basis of equations (5), in which the dashed deviations of the variables were considered normalized to the corresponding mean values, and the effect coefficients were calculated using the formulas (4): 


$$
\begin{aligned}
& \frac{d P P}{d t}=2 r_{P P} P P\left\{C_{P P}-\left[P P-C_{P P}\left(a_{14} N O_{3}^{\prime}+a_{15} N H_{4}^{\prime}-a_{16} D O N^{\prime}-a_{12} Z^{\prime}-\right.\right.\right. \\
& \left.\left.\left.-a_{17} D^{\prime}-a_{18} P L^{\prime}\right)\right]\right\}, \\
& \frac{d Z}{d t}=2 r_{Z} Z\left\{C_{Z}-\left[Z-C_{Z}\left(a_{21} P^{\prime}+a_{23} B^{\prime}-a_{25} N H_{4}^{\prime}-a_{26} D O N^{\prime}-a_{28} P L^{\prime}\right)\right]\right\}, \\
& \frac{d B}{d t}=2 r_{B} B\left\{C_{B}-\left[B-C_{B}\left(a_{36} D O N^{\prime}-a_{32} Z^{\prime}-a_{35} N H_{4}^{\prime}-a_{38} P L^{\prime}\right)\right]\right\}, \\
& \frac{d N O_{3}}{d t}=2 r_{N O_{3}} N O_{3}\left\{C_{N O_{3}}-\left[N O_{3}-C_{N O_{3}}\left(a_{45} N H_{4}^{\prime}+a_{46} D O N^{\prime}-a_{41} P^{\prime}\right)\right]\right\}, \\
& \frac{d N H_{4}}{d t}=2 r_{N H_{4}} N H_{4}\left\{C_{N H_{4}}-\left[N H_{4}-C_{N H_{4}}\left(a_{52} Z^{\prime}+a_{53} B^{\prime}+a_{56} D O N^{\prime}-\right.\right.\right. \\
& \left.\left.\left.-a_{51} P^{\prime}-a_{54} N O_{3}^{\prime}\right)\right]\right\}, \\
& \frac{d D O N}{d t}=2 r_{D O N} D O N\left\{C_{D O N}-\left[D O N-C_{D O N}\left(a_{61} P^{\prime}+a_{62} Z^{\prime}+a_{67} D^{\prime}-a_{63} B^{\prime}-\right.\right.\right. \\
& \left.\left.\left.-a_{64} N O_{3}^{\prime}-a_{65} N H_{4}^{\prime}\right)\right]\right\}, \\
& \frac{d D}{d t}=2 r_{D} D\left\{C_{D}-\left[D-C_{D}\left(a_{71} P^{\prime}+a_{72} Z^{\prime}-a_{76} D O N^{\prime}\right)\right]\right\} .
\end{aligned}
$$

This system of equations was supplemented with equations for the concentration of pollutants

$$
\frac{d P L}{d t}=2 r_{P L} P L\left\{C_{P L}-\left[P L-C_{P L}\left(a_{P L / V} V^{\prime}-A G\left[T X_{\text {acc }}, T X_{\text {acc }}^{*}\right]\right)\right]\right\},
$$

which affected the ecosystem biological variables, as well as the equation for the biodiversity index

$$
\begin{gathered}
\frac{d B D}{d t}=2 r_{B D} B D\left\{C_{B D}-\left[B D-A G_{B D}(P P, Z P, B)\right]\right\} ; \\
A G_{B D}(P P, Z P, B)=C_{B D} \arg \min \left(C_{P P}^{-1} P P ; C_{Z P}^{-1} Z P ; C_{B}^{-1} B\right) .
\end{gathered}
$$

It should be noted that the agent of the biodiversity index $A G_{B D}(P P, Z P, B)$ controlled the value of this index for that of the species of living organisms in the ecosystem, which had the lowest concentration in comparison with other organisms at a given moment of time. Therefore, an increase in the concentration of one of the species did not mean an increase in the biodiversity index, unless this species was the limiting one for the index.

Economic part of the coastal runoff - sea bay model included an equation for the demand for the generalized product of the coastal system $D P$

$$
\frac{d D P}{d t}=2 r_{D P} D P\left[C_{D P}-\left(D P+a_{D P / P P} P P^{\prime}\right)\right]
$$


and the equation for the production cost $E$

$$
\frac{d E}{d t}=2 r_{E} E\left[C_{E}-\left(E-a_{E / T X} T X^{\prime}-E^{*}\right)\right]
$$

Into the equation for the production output volumes $V$

$$
\frac{d V}{d t}=2 r_{V} V\left\{C_{V}-\left[V-a_{V / D P} D P^{\prime}+A G_{V}(P, E)+A G_{V}\left(B D, B D^{*}\right)\right]\right.
$$

the agents for managing the production profitability

$$
A G_{V}(P, E)=I F\left\{P>E ; 0 ; C_{V}\left[1-\exp \left(-\alpha_{V / P} \tau\right)\right]\right\}
$$

and marine environment biodiversity level were included.

$$
A G_{V}\left(B D, B D^{*}\right)=I F\left\{B D>B D^{*} ; 0 ; C_{V}\left[1-\exp \left(-\alpha_{V / B D} \tau\right)\right]\right\} .
$$

For assessing the profitability, the integral estimate $E F$ was applied in the form of the logarithm of the system's income $\boldsymbol{I}_{\text {acc }}$ ratio over time period $(0, t)$ to the costs $E_{\text {acc }}$ for the same period:

$$
I_{\mathrm{acc}}=\int_{0}^{t} P(t) V(t) d t, \quad E_{\mathrm{acc}}=\int_{0}^{t} E(t) V(t) d t, \quad E F=\ln \frac{1+I_{\mathrm{acc}}}{1+E_{\mathrm{acc}}} .
$$

Profitability management was carried out through the penalties $T X$ for marine pollution, which were calculated using the equation

$$
\frac{d T X}{d t}=2 r_{T X} T X\left\{C_{T X}-\left[T X-a_{T X / P L} A G_{T X / P L}\left(P L, P L^{*}\right)\right]\right\} .
$$

The management agent $A G_{T X / P L}\left(P L, P L^{*}\right)$ set the amount of fine in proportion to the pollution concentration value as long as it did not exceed the maximum permissible value $P L^{*}$. Otherwise, the penalty increased exponentially up to $P L^{*}$ double value:

$$
A G_{T X / P L}\left(P L, P L^{*}\right)=I F\left\{P L<P L^{*}, P L ; 2 P L^{*}\left[1-\exp \left(-\gamma_{T X} \tau\right)\right]\right\} .
$$

It was assumed that the penalties are accumulated in a special fund of new technologies $T X_{\text {acc }}$ designed for treatment the coastal runoff from pollution. For this purpose, in the management model it was envisaged an agent that included in equation (9) the runoff treatment mode when the fund size reached the value $T X_{\text {acc }}^{*}$ :

$$
A G\left(T X_{\mathrm{acc}}, T X_{\mathrm{acc}}^{*}\right)=I F\left\{T X_{\mathrm{acc}},<T X_{\mathrm{acc}}^{*} ; 0 ; C_{P L}[1-\exp (-\delta \tau)]\right\} .
$$

The initial conditions for constructing scenarios of ecological and economic processes were the average long-term values of all variables, which were assumed to be known from observations. Each of the model equations was supplemented with conditions (3) that controlled the finding of variables within their definition domains. 
Discussion and conclusion. For testing the model, we used observational data in the coastal runoff - Sevastopol Bay system. Shipbuilding and ship repair enterprises, food industry enterprises, oil depots, thermal power plant, "Krymvtormet" enterprise, the infrastructure of the military, fish and cargopassenger ports and military units are located directly in the coastal zone of Sevastopol. As is shown in [16], the annual wastewater discharge into the Sevastopol Bay is estimated at 2 million $\mathrm{m}^{3}$, emergency discharges and storm runoffs amount to about 1.5 million $\mathrm{m}^{3}$. At least 1000 tons of suspended matters, 52 tons of mineral nitrogen and 6 tons of phosphorus inflow the bay every year [14, 16, 22] with the Chernaya River waters.

In Fig. 2 the scenarios of coastal runoff management according to the scheme (see Fig. 1) under the conditions of constant demand for a generalized product and constant cost of this product are given.

The following mean long-term values of substance concentrations $\left(\mathrm{mg} \cdot \mathrm{N} / \mathrm{m}^{3}\right)$ were taken for the stationary state of the bay ecosystem: $C_{P}=37,74, C_{Z}=18,87, C_{B}=15, C_{\mathrm{NO}_{3}}=42,35, C_{\mathrm{NH}_{4}}=5,60, C_{D}=15$. In addition, the average annual variation of bacterial plankton concentration over the bay area was used. The calculations based on model (6)-(17) were performed for 365 days of a conditional year.
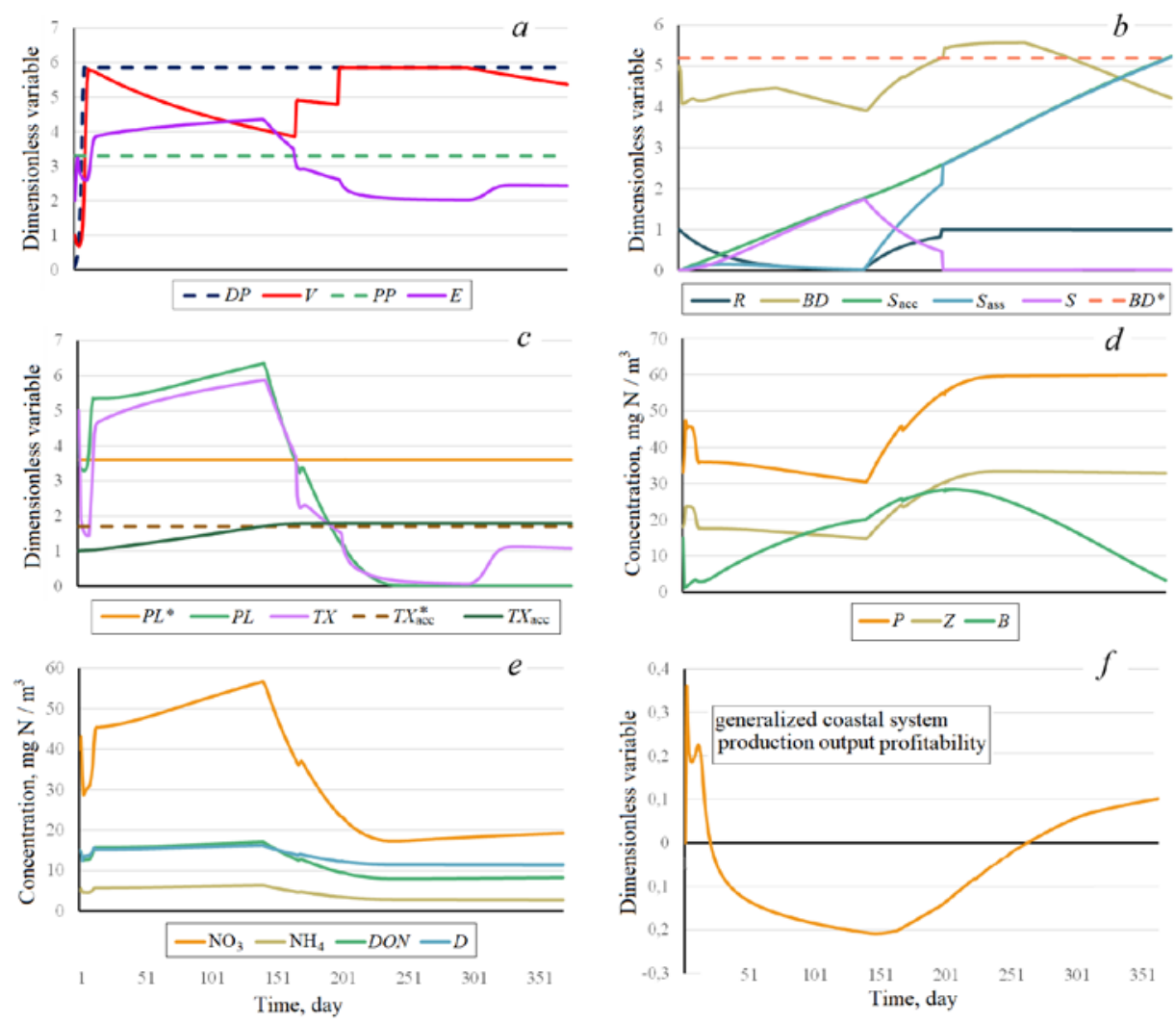

F i g. 2. Managing the scenarios of the economic $(a, b, f)$ and environmental $(c, d, e)$ processes calculated based on the long-term data on the Sevastopol Bay ecosystem state 
As follows from Fig. 2, $a, c$, at the beginning of the experiment the pollutant runoff exceeded the assimilation capacity of the bay, the assimilation capacity agent exponentially decreased $R(t)$ index value, and pollutant accumulation rate $S_{\text {acc }}$ significantly outpaced the rate of their destruction $S_{\text {ass }}$ (Fig. 2, $b$ ). The pollution concentration in the sea $P L$ significantly exceeded the maximum permissible value $P L^{*}$ (Fig. 2, c), and biodiversity level $B D$ was below the permissible value $B D^{*}$ (Fig. 2, b). Therefore, management agents began to restrict the output of products, and, consequently, the rate of pollution inflow into the sea (Fig. 2, c). The amount of penalties $T X$ for pollution decreased (Fig. 2, $c$ ) and the production cost $E$ became lower than the product cost $P P$ (Fig. 2, a) at the $166^{\text {th }}$ step of the experiment. However, the integral production profitability remained negative (Fig. 2, f).

This situation persisted until the $140^{\text {th }}$ step of calculations, when the amount of funds accumulated in the new technologies fund reached the established value $T X_{\text {acc }}^{*}=1,7$ conventional units. Starting from this time moment, the agent for pollution runoff treatment imitated the use of new technologies for preliminary treatment, as a result of which the concentration of pollutants $P L$ began to decrease sharply (Fig. 2, c). At the same time, the concentrations of phyto- and zooplankton began to increase (Fig. 2, $d$ ) which ultimately led to an increase in the biodiversity index $B D$. At the $200^{\text {th }}$ step of the calculations it exceeded the permissible value of $B D^{*}=5,2$ conventional units. Note that the average long-term scenario of bacterial plankton concentration used in the calculations (Fig. 2, $d$ ) was a limiting factor in estimating the biodiversity value.

After restoring the balance of pollution accumulation and assimilation rates, the assimilation capacity agent took $R(t)=1$ value (Fig. 2, b), the production limitation was removed and the production volume increased to the demand level DP (Fig. 2, a).

From this time point, the production profitability began to increase rapidly, despite significant penalties applied to the economic system in the initial period of the experiment, and at the $270^{\text {th }}$ step it reached positive values (Fig. 2, f).

Conclusions. Thus, computational experiments have confirmed the property of the proposed adaptive model to predict scenarios of ecological and economic processes that are consistent with the management concepts embedded in the model. The applied method of estimating the coefficients of the adaptive model equations by the normalized current ratios of the process average values made provided the construction of the coast - bay system quantitative model based on the minimum volume of observations - the average long-term values of the simulated processes. The ability to simulate model responses to various options for external control actions makes such models a convenient tool for planning environmental actions in coast - bay systems. 


\section{REFERENCES}

1. Daly, H. and Farley, J., 2010. Ecological Economics: Principles and Applications. Washington, DC: Island Press, 544 p.

2. Voinov A. 2008. Systems Science and Modeling for Ecological Economics. New York: Academic Press, 432 p.

3. Shogren, J.F., Parkhurst, G.M. and Settle, C., 2003. Integrating Economics and Ecology to Protect Nature on Private Lands: Models, Methods, and Mindsets. Environmental Science \& Policy, 6(3), pp. 233-242. https://doi.org/10.1016/S1462-9011(03)00041-8

4. $\quad$ Crépin, A.-S., Norberg, J. and Mäler, K.-G., 2011.Coupled Economic-Ecological Systems with Slow and Fast Dynamics - Modelling and Analysis Method. Ecological Economics, 70(8), pp. 1448-1458. https://doi.org/10.1016/j.ecolecon.2011.02.004

5. Pearce, D. and Moran, D., 1994. The Economic Value of Biodiversity. London: Earthscan, 172 p. Available at: https://is.gd/S3Wb9Y [Accessed: 10 April 2020].

6. Timchenko, I.E., Igumnova, E.M. and Timchenko, I.I., 2000. [System Management and ABCTechnologies of Sustainable Development]. Sevastopol: ECOSI-Gidrofizika, 225 p. (in Russian).

7. Izrael, Y.A., Tsiban, A.V., Ventzel, M.V. and Shigaev, V.V., 1988. Scientific Basis for Ecological Standartization of the Man-Made Effect on Marine Ecosystem are Taken for the Baltic Sea. Oceanology, 28(2), pp. 293-299.

8. Ivanov, V.A., Igumnova, E.M. and Timchenko, I.E., 2012. Coastal Zone Resources Management. Kiev: Academperiodika, 304 p. https://doi.org/10.15407/akademperiodyka.192.304

9. Ofiara, D.D. and Seneca, J.J., 2001. Economic Losses from Marine Pollution: A Handbook for Assessment. Washington, DC: Island Press, 320 p.

10. Costanza, R., Voinov, A., Boumans, R., Maxwell, T., Villa, F., Wainger, L. and Voinov, H., 2002. Integrated Ecological Economic Modeling of the Patuxent River Watershed, Maryland. Ecological Monographs, 72(2), pp. 203-231. https://doi.org/10.1890/00129615(2002)072[0203:IEEMOT]2.0.CO;2

11. Samhouri, J.F. and Levin, P.S., 2012. Linking Land- and Sea-Based Activities to Risk in Coastal Ecosystems. Biological Conservation, 145(1), pp. 118-129. https://doi.org/10.1016/j.biocon.2011.10.021

12. Halpern, B.S., Walbridge, S., Selkoe, K.A., Kappel, C.V., Micheli, F., D'Agrosa, C., Bruno, J.F., Casey, K.S. and Ebert, C. [et al.], 2008. A Global Map of Human Impact on Marine Ecosystems. Science, 319(5865), pp. 948-952. doi:10.1126/science.1149345

13. Elofsson, K., Folmer, H. and Grey, I.-M., 2003. Management of Eutrophicated Coastal Ecosystems: a Synopsis of the Literature with Emphasis on Theory and Methodology. Ecological Economics, 47(1), pp. 1-11. https://doi.org/10.1016/j.ecolecon.2003.09.001

14. Orekhova, N.A. and Varenik, A.V., 2018. Current Hydrochemical Regime of the Sevastopol Bay. Physical Oceanography, 25(2), pp. 124-135. doi:10.22449/1573-160X-2018-2-124-135

15. Börger, T., Beaumont, N.J., Pendleton, L., Boyle, K.J., Cooper, P., Fletcher, S., Haab, T., Hanemann, M., Hooper, T.L., 2014. Incorporating Ecosystem Services in Marine Planning: the Role of Valuation. Marine Policy, 46, pp. 161-170. https://doi.org/10.1016/j.marpol.2014.01.019

16. Ivanov, V.A., Ovsyany, E.I., Repetin, L.N., Romanov, A.S. and Ignatyeva, O.G., 2006. [Hydrological and Hydrochemical Regime of the Sebastopol Bay and its Changing under Influence of Climatic and Anthropogenic Factors]. Sevastopol: MHI, 90 p. (Preprint). Available at: http://mhi-ras.ru/assets/files/gidrologogidrohimicheskij_rezhim_sevastopolskoj_buhty_2006.pdf [Accessed: 19 May 2020] (in Russian).

17. Fasham, M., Ducklow, H. and McKelvie, S., 1990. A Nitrogen-Based Model of Plankton Dynamics in the Oceanic Mixed Layer. Journal of Marine Research, 48(3), pp. 591-639. https://doi.org/10.1357/002224090784984678 
18. Timchenko, I.E., Ivashchenko, I.K. and Igumnova, E.M., 2017. Management of EcologicalEconomic Processes of Pollution Accumulation and Assimilation in the Coastal Zone Marine Environment. Physical Oceanography, (1), pp. 68-83. doi:10.22449/1573-160X-2017-1-68-83

19. Timchenko, I.E., Igumnova, E.M. and Timchenko, I.I., 2016. Adaptive Balance Models for Environmental-Economic Systems. CreateSpace Independent Publishing Platform, 486 p.

20. Timchenko, I.E., Igumnova, E.M. and Svishchev, S.V., 2019.Application of the Principles of the Marine Ecosystems' Adaptive Modeling to the Hydrochemical Observations in the Sevastopol Bay. Physical Oceanography, 26(1), pp. 63-76. doi:10.22449/1573-160X2019-1-63-76

21. Svishchev, S.V., 2018. Adaptive Modeling of Nitrification in the Sevastopol Bay. Ekologicheskaya Bezopasnost' Pribrezhnoy i Shel'fovoy Zon Morya = Ecological Safety of Coastal and Shelf Zones of Sea, (2), pp. 60-65. doi:10.22449/2413-5577-2018-2-60-65 (in Russian).

22. Sovga, E.E., Mezentseva, I.V., Khmara, T.V. and Slepchuk, K.A., 2014. [On the Prospects and Opportunity to Assess the Self-Purifying Capacity of the Sevastopol Bay]. In: V.A. Ivanov, ed., 2014. Ekologicheskaya Bezopasnost' Pribrezhnoy i Shel'fovoy Zon i Kompleksnoe Ispol'zovanie Resursov Shel'fa [Ecological Safety of Coastal and Shelf Zones and Comprehensive Use of Shelf Resources]. Sevastopol: MHI NANU. Issue 28, pp. 153-164 (in Russian).

About the authors:

Igor E. Timchenko - Deputy Chief Editor, Head of System Analysis Department, Marine Hydrophysical Institute of RAS (2 Kapitanskaya St., Sevastopol, 299011, Russian Federation), Dr. Sci. (Phys.-Math.), Professor, ResearcherID: A-8650-2017, ORCID ID: 0000-0003-4673-7609, timchenko.syst.analysis@mhi-ras.ru

Igor. K. Ivashchenko - Assistant Editor, Senior Research Associate, Marine Hydrophysical Institute of RAS (2 Kapitanskaya St., Sevastopol, 299011, Russian Federation), Ph. D. (Econ.), SPINcode: 7626-4616 Author ID: 941046, journal@mhi-ras.ru

Ekaterina M. Igumnova - Leading Engineer, Marine Hydrophysical Institute of RAS (2 Kapitanskaya St., Sevastopol, 299011, Russian Federation), SPIN-code: 5950-7785 Author ID: 861018, igumnova.syst.analysis@mhi-ras.ru

Sergey V. Svishchev - Junior Research Associate, Marine Hydrophysical Institute of RAS (2 Kapitanskaya St., Sevastopol, 299011, Russian Federation), ResearcherID: T-1962-2018, ORCID ID: 0000-0003-4673-7609, sergsvishchev09@gmail.com

Contribution of the co-authors:

Igor E. Timchenko - research organization and its management, development and application of Adaptive Balance of Causes Method for managing scenarios of ecological and economic processes in the "Coast - sea" system, analysis of research results

Igor. K. Ivashchenko - discussion of the economic part structure of "coastal runoff - coastal marine environment” ecological and economic system model

Ekaterina M. Igumnova - construction of a conceptual model of the ecological and economic system “coastal runoff - coastal marine environment”, preparing and carrying out computational experiments with the model

Sergey V. Svishchev - development of a sea bay ecosystem model, construction of model equations, preparation of biochemical observation data, analysis of research results

The authors have read and approved the final manuscript.

The authors declare that they have no conflict of interest. 